\title{
In vitro efficacy of new antiprotozoals against Philasterides dicentrarchi (Ciliophora, Scuticociliatida)
}

\author{
A. Paramá ${ }^{1}$, R. Iglesias ${ }^{2}$, F. Álvarez ${ }^{1}$, J. M. Leiro ${ }^{1}$, J. M. Quintela ${ }^{3}$, C. Peinador ${ }^{3}$, \\ L. González ${ }^{3}$, R. Riguera ${ }^{4}$, M. L. Sanmartín ${ }^{1, *}$ \\ ${ }^{1}$ Laboratorio de Parasitología, Instituto de Investigación y Análisis Alimentarios, Universidad de Santiago de Compostela, \\ 15782 Santiago de Compostela, Spain \\ ${ }^{2}$ Área de Parasitología, Departamento de Biología Funcional y Ciencias de la Salud, Facultad de Ciencias, \\ Campus Lagoas/Marcosende s/n, Universidad de Vigo, 36200 Vigo, Spain \\ ${ }^{3}$ Departamento de Química Fundamental e Industrial, Facultad de Ciencias, Universidad de La Coruña, \\ 15701 La Coruña, Spain \\ ${ }^{4}$ Departamento de Química Orgánica, Facultad de Química, Instituto de Acuicultura, \\ Universidad de Santiago de Compostela, 15782 Santiago de Compostela, Spain
}

\begin{abstract}
Philasterides dicentrarchi is a histiophagous ciliate that causes severe losses in turbot and sea bass farming. This study investigated the in vitro efficacy against $P$. dicentrarchi of 85 newly synthesized compounds and 12 commercial compounds, of which 2 are fluoroquinolones (norfloxacine and lomefloxacine) with known antibacterial activity. Seventeen of the newly synthesized compounds (2 naphthyridines, 2 pyridothienodiazines and 13 pyridothienotriazines) and the fluoroquinolone norfloxacin showed good activity. The most promising compound was the pyridothienotriazine $12 \mathrm{k}$, with activity similar to that of the salicylanilides niclosamide and oxiclozanide (MLC $0.8 \mathrm{mg} \mathrm{l}^{-1}$ in PBS, $1.5 \mathrm{mg} \mathrm{l}^{-1}$ in seawater; MLC = minimum $24 \mathrm{~h}$ lethal concentration).
\end{abstract}

KEY WORDS: Philasterides dicentrarchi $\cdot$ Turbot $\cdot$ Scuticociliatosis $\cdot$ In vitro assay $\cdot$ Naphthyridines · Pyridothienotriazines · Pyridothienodiazines

Resale or republication not permitted without written consent of the publisher

\section{INTRODUCTION}

Philasterides dicentrarchi is a histiophagous scuticociliate that provokes significant economic losses in aquaculture, through systemic infection of gilthead bass (Dragesco et al. 1995) and turbot (Iglesias et al. 2001). In turbot farms, the incidence of this disease appears to have increased in recent years, to the extent that it is now one of the most significant parasite pathologies. No effective control measures are currently available. This parasite may be readily and rapidly eliminated while it remains outside the host body by formalin baths (Iglesias et al. 2002); however, once it has penetrated the body and initiated endoparasitic infection, this treatment is no longer effective.
One of the major problems in aquatic parasitology is the need for chemotherapeutical agents to be harmless for the aquatic environment and the host at doses effective against the parasite. This, together with the high mutation and genetic recombination rates of parasitic protozoans (Wang 1984), is possibly the reason why these protozoans develop drug resistance so quickly. This makes the identification of effective chemotherapeutical compounds very difficult (Wang 1984), slowing down the development of new antiprotozoal agents and making their modes of action difficult to study. We have recently reported a study of the in vitro activity against Philasterides dicentrarchi of a series of known antiprotozoal drugs (Iglesias et al. 2002), but to date there are still no fully effective con- 
trol measures against this ciliate in vivo. Activity studies of new drugs must thus continue.

In the present study, we investigated the susceptibility of Philasterides dicentrarchi to 85 newly synthesized antiprotozoals and 12 commercial compounds, of which two (norfloxacin and lomefloxacin) are commercial antibiotics with known antibacterial activity. This approach facilitated the identification of structurefunction relationships. Preliminary activity data for compounds 2f, 5o, 12d, 12f, 12h, 12k, 12m, 7h, 9 and the antibacterials, together with synthesis routes and structural characteristics for many of the new drugs tested here, have been published recently (Quintela et al. 1999, 2003a).

\section{MATERIALS AND METHODS}

Isolation and culture of Philasterides dicentrarchi. Ciliates were harvested by collecting ascitic fluid from the body cavity of naturally infected turbot and were maintained under the culture conditions described by Bernard \& Fenchel (1996), with autoclaved Vibrio anguillarum as food source. The cultured ciliates maintained infectivity in experimental infection trials.

Drugs. The drugs tested were 85 newly synthesized compounds and 12 commercial compounds belonging to the following chemical groups: (1) simple piperazines: PI-1, PI-2, PI-3, PI-4, PI-5, PI-6 (synthesized as per Raviña et al. 1996), PI-8, PI-9 (Raviña et al. 1995), PI-10 (Raviña et al. 1999), PI-12 (Estévez et al. 1998) and the commercial simple piperazines PCP (piperazine citrate pentahydrate, FLUKA), PDH-1 (piperazine dihydrochloride hydrate, FLUKA), PCA-1 (S-2 piperazine carboxylic acid dihydrochloride, FLUKA), PNP (1-phenylpiperazine, SIGMA), P2C (1-(2-chlorophenyl) piperazine monohydrochloride, SIGMA), P3C (1-(3-chlorophenyl) piperazine hydrochloride, SIGMA), P4C (1-(4-chlorophenyl) piperazine dihydrochloride, SIGMA), PBF (1- $(\alpha, \alpha, \alpha$-trifluoro-m-tolyl) piperazine, SIGMA), PAC (4'-piperazinoacetophenone, SIGMA), CNP (trans-1-cinnamylpiperazine, SIGMA), norfloxacin (PN in Table 1) and lomefloxacin (PL in Table 1) (SIGMA, ALDRICH). (2) Naphthyridines 2b, 2d, 2e, 2f, 2g, 2i, 2j, 2k, 5 o (synthesized as per Quintela et al. 2003a). (3) Pyridothienodiazines 3a, 4e, 4g, 4i, 4l, 8a, 9e, 9f, 9g, 9j, 91 and 7 (Quintela et al. 1998a), and compound H-26 with the same skeleton as $9 \mathrm{~g}$ but differing in that its ethoxy substituent has been replaced by a phenyl group and the N-4'-acetyl piperazino substituent by a $\mathrm{N}$-piperazine group. (4) Pyridothienotriazines: compounds 6a, 7a, 7d, 7f, 7g, $7 \mathrm{~h}, 7 \mathrm{i}, 8 \mathrm{a}, 8 \mathrm{~b}$ and 9 (synthesized as per Quintela et al. 1998b), compounds 12d,12i, 12l, 14 and 16 (as per Quintela et al. 1999), and compounds 12c, 12e, 12f,
$12 \mathrm{~g}, 12 \mathrm{~h}, 12 \mathrm{k}$ and $12 \mathrm{~m}$ (synthesized as per Quintela et al. 2003a). (5) Pyridines: compounds 8, 22, 23, 24, 25, 28 and 31 (synthesized as per Quintela et al. 1997). (6) Pyrazolopyrimidines: compounds 3c, 4b, 4c, 6c, 9b and 9c (synthesized as per Quintela et al. 2003b). (7) Isoxazolpyrimidines: compounds IOP-2 and IOP-5 (synthesized as per Vidal et al. 2000), and other compounds with the same skeleton as IOP-2 but with Nmorpholino (BR-46), N-thiomorpholino (BR-47), thiol (BR-100), N-4'-acetylphenylpiperazino (BR-101) and $\mathrm{N}$-diethyl (BR-102) substituents in place of the $\mathrm{N}$ propyl group. (8) Pyrimidines: compound 6 (synthesized as per Quintela et al. 2003a), compounds 35, 37 , 39, 41 and 45 (synthesized as per Quintela et al. 1997), compound PPC-19 with the same skeleton as 35 but differing in that its phenyl substituent has been replaced by a 4-chlorophenyl group and the N-4methylpiperidino by a N-4-aminopyridine group. Compounds LLC-62, LLC-63, LLC-66 and LLC-72 present the same skeleton as compound 6 but LLC-62 has an N-morpholino substituent in place of the $\mathrm{N}$-thiomorpholino, LLC-72 has an N-morpholino in place of the N-piperazine substituent, LLC-63 has an $\mathrm{N}$-morpholino instead of the N-thiomorpholino substituent and a N-4-methylpiperazino instead of the Npiperazine substituent, and LLC-66 has a thiomorpholino group instead of the piperazino and a morpholino instead of the thiomorpholino of compound 6 .

Susceptibility testing. Stock solutions of the compounds were made up at $0.1 \mathrm{mg} \mathrm{ml}^{-1}$ in dimethyl sulfoxide (DMSO; Sigma Chemical) and serial dilutions were prepared in physiological phosphatebuffered saline (PBS, pH 7.2) or $0.2 \mu \mathrm{m}$ filtered seawater (salinity $28 \%$ ) to give the final concentrations tested $\left(100,50,25,12.5,6.2,3.1,1.5\right.$ and $\left.0.8 \mathrm{mg} \mathrm{l}^{-1}\right)$. The compounds were tested in seawater with the aim of evaluating whether or not they maintain their activity in this medium.

For testing, ciliates in late exponential or early plateau phase were concentrated by centrifugation at $650 \times g$ for $5 \mathrm{~min}$ and resuspended in PBS or filtered seawater. After counting in a haematocrit, $10 \mu$ l of the suspension containing $10^{4}$ ciliates was added to each well of 96-well polystyrene microtitre plates containing $90 \mu \mathrm{l}$ per well of the candidate antiprotozoal at the test dose, in PBS or filtered seawater. The plates were incubated at $18^{\circ} \mathrm{C}$ for $24 \mathrm{~h}$.

Each dilution was assayed in duplicate and compared with a negative control containing the ciliates in the test solution (PBS or filtered seawater) without the test drug. To rule out possible toxic effects of the solvent DMSO, we also included duplicate wells containing the highest concentration of DMSO (2.5\%) but no test drug. DMSO was observed not to cause significant mortality or any other obvious toxic effect. 
The effects of each test drug were assessed using an inverted microscope with phase-contrast illumination. Results are expressed as minimum lethal concentration (MLC), i.e. the minimum concentration required to cause $100 \%$ ciliate mortality.

\section{RESULTS AND DISCUSSION}

Some of the compounds analyzed caused noticeable reductions in ciliate motility and morphological alter- ations (cell rounding, vacuolization, eventual cell lysis, see Fig. 1). Drugs effective against Philasterides dicentrarchi must be able to eradicate all the ciliates present because fecundity and invasiveness of surviving ciliates (Iglesias et al. 2001) will give way to a new infection within a few days.

The antiparasitic activity of compounds with a piperazine ring is well documented and in fact, piperazine and its salts are widely used in veterinary medicine. We thus performed additional assays to assess the susceptibility of Philasterides dicentrarchi to newly syn-

Table 1. In vitro activities of the compounds tested against Philasterides dicentrarchi for $24 \mathrm{~h}$ dissolved in PBS or seawater. Results are expressed as MLC (minimum lethal concentration in $\mathrm{mg}^{-1}$ )

\begin{tabular}{|c|c|c|c|c|c|c|}
\hline & Compound & PBS & Seawater & Compound & PBS & Seawater \\
\hline \multirow[t]{12}{*}{ Simple piperazines } & $\mathrm{PN}$ & 50 & 50 & PI-1 & - & - \\
\hline & PL & - & - & PI-2 & - & - \\
\hline & PCP & - & - & PI-3 & - & - \\
\hline & PDH-1 & - & - & PI-4 & - & - \\
\hline & PCA-1 & - & - & PI-5 & - & - \\
\hline & PNP & - & - & PI-6 & - & - \\
\hline & $\mathrm{P} 2 \mathrm{C}$ & - & 100 & PI-8 & 100 & 50 \\
\hline & P3C & - & 100 & PI-9 & - & - \\
\hline & $\mathrm{P} 4 \mathrm{C}$ & 100 & - & PI-10 & - & - \\
\hline & PBF & - & 100 & PI-12 & - & - \\
\hline & PAC & - & - & & & \\
\hline & CNP & - & 100 & & & \\
\hline \multirow[t]{5}{*}{ Naphthyridines } & $2 b$ & - & - & $2 \mathrm{i}$ & - & - \\
\hline & $2 d$ & - & - & $2 j$ & - & - \\
\hline & $2 e$ & 100 & - & $2 \mathrm{k}$ & - & - \\
\hline & $2 f$ & 50 & 12.5 & 50 & 25 & 12.5 \\
\hline & $2 g$ & - & - & & & \\
\hline \multirow[t]{7}{*}{ Pyridothienodiazines } & $3 a$ & - & - & $9 \mathrm{e}$ & - & - \\
\hline & $4 \mathrm{e}$ & - & - & 9f & - & - \\
\hline & $4 \mathrm{~g}$ & - & - & $9 g$ & - & - \\
\hline & $4 \mathrm{i}$ & - & - & $9 \mathrm{j}$ & - & - \\
\hline & 41 & - & - & 91 & - & - \\
\hline & $8 a$ & - & - & 7 & 12.5 & 12.5 \\
\hline & $\mathrm{H}-26$ & 50 & - & & & \\
\hline \multirow[t]{11}{*}{ Pyridothienotriazines } & $6 a$ & 3.1 & - & $12 \mathrm{~d}$ & 50 & 12.5 \\
\hline & $7 a$ & - & - & $12 \mathrm{e}$ & 50 & - \\
\hline & $7 d$ & - & - & $12 \mathrm{f}$ & 25 & 12.5 \\
\hline & $7 f$ & - & - & $12 \mathrm{~g}$ & 100 & 50 \\
\hline & $7 g$ & 25 & - & $12 \mathrm{~h}$ & 25 & 25 \\
\hline & $7 \mathrm{~h}$ & 6.2 & 3.1 & $12 \mathrm{i}$ & 100 & 50 \\
\hline & $7 \mathrm{i}$ & - & - & $12 \mathrm{k}$ & 0.8 & 1.5 \\
\hline & $8 a$ & - & - & 121 & - & - \\
\hline & $8 b$ & - & - & $12 \mathrm{~m}$ & 25 & 25 \\
\hline & 9 & 25 & 25 & 14 & - & - \\
\hline & $12 \mathrm{c}$ & 50 & 100 & 16 & - & - \\
\hline \multirow[t]{4}{*}{ Isoxazolpyrimidines } & IOP-2 & - & - & BR-100 & - & - \\
\hline & IOP-5 & - & - & BR-101 & - & - \\
\hline & BR-46 & - & - & BR-102 & 100 & 100 \\
\hline & BR-47 & - & - & & & \\
\hline \multirow[t]{6}{*}{ Pyrimidines } & 6 & 100 & - & PPC-19 & 100 & 100 \\
\hline & 35 & - & - & LLC-62 & - & - \\
\hline & 37 & - & - & LLC-63 & - & - \\
\hline & 39 & - & - & LLC-66 & - & - \\
\hline & 41 & - & - & LLC-72 & - & - \\
\hline & 45 & - & - & & & \\
\hline
\end{tabular}




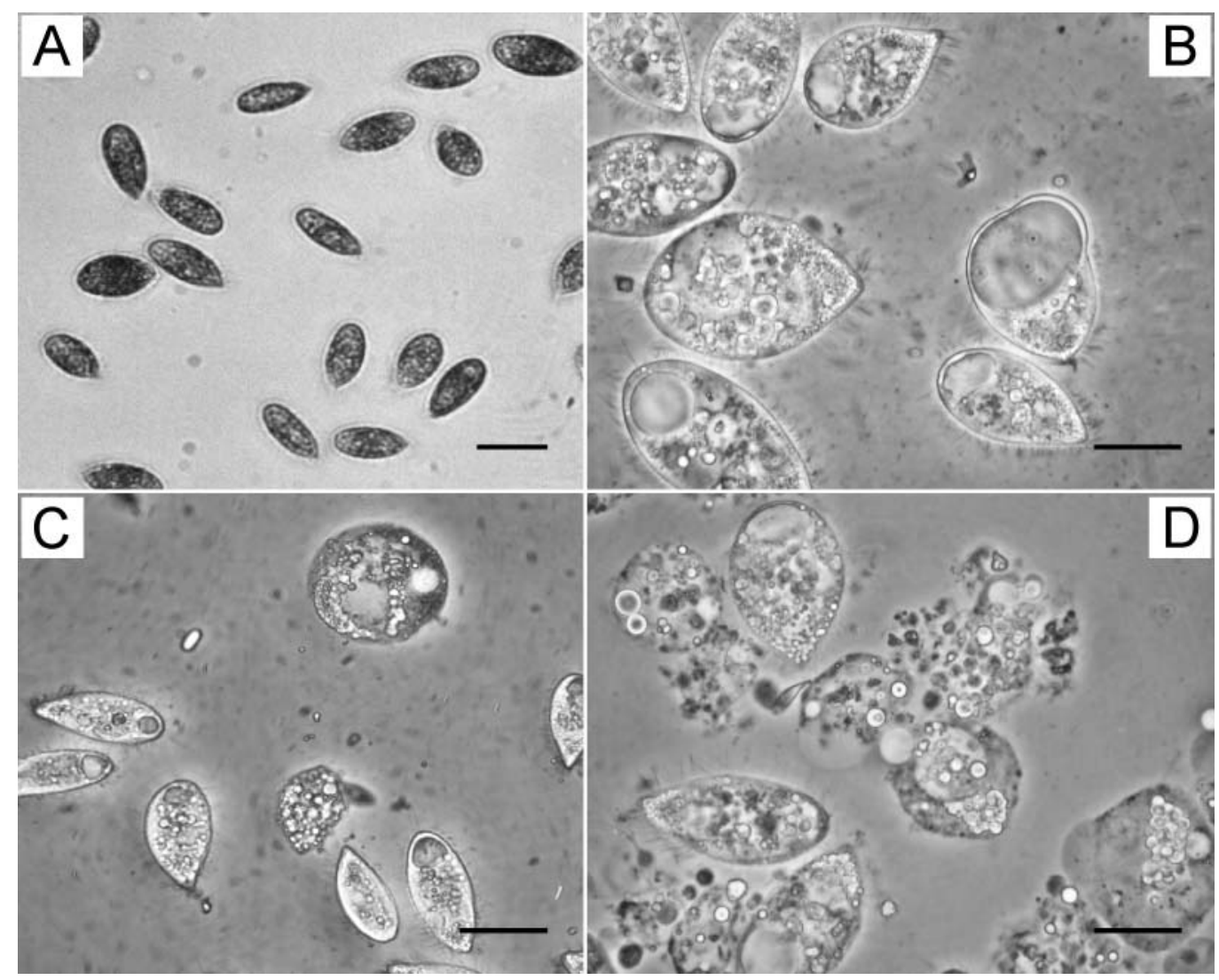

Fig. 1. Philasterides dicentrarchi. Micrographs showing effects of the active compounds on morphology: (A) normal culture, no drug $($ scale bar $=40 \mu \mathrm{m}) ;(B)$ drug-induced vacuole formation $($ scale bar $=15 \mu \mathrm{m}) ;(\mathrm{C})$ drug-induced cell rounding $($ scale bar $=$ $24 \mu \mathrm{m}) ;(\mathrm{D})$ drug-induced lysis (scale bar $=15 \mu \mathrm{m}$ )

thesized and commercial simple piperazines. Previous studies indicate that various pathogenic freshwater protozoans and metazoans infecting trout are not effectively killed by piperazines (Icthyobodo necator, Tojo \& Santamarina 1998a; Gyrodactylus spp., Tojo \& Santamarina 1998b; Hexamita salmonis, Tojo \& Santamarina 1998c). Our results (Table 1) show that several of these compounds are effective, though in some cases at very high concentrations (i.e. MLC $100 \mathrm{mg} \mathrm{l}^{-1}$; see Table 1).

Norfloxacin and lomefloxacin are fluoroquinolone (fluorated quinolone) derivates of the piperazine chemical group. These compounds are widely used, in view of their high bioavailability after oral administration and relatively minor adverse effects in humans (Céspedes \& Portal 1998). Fluoroquinolones act by inhibiting topoisomerase II, a key enzyme in DNA transcription and replication in both eukaryotes and prokaryotes (Drlica \& Franco 1988), and have a wide antibacterial spectrum (Montay et al. 1984, Brun-Pascaud et al. 1992). In spite of the chemical structure of fluoroquinolones being very similar, these small structural changes give rise to differences in their biological characteristics; so norfloxacin is effective against Philasterides dicentrarchi at a dose of $50 \mathrm{mg} \mathrm{l}^{-1}$ in both PBS and seawater, while lomefloxacin does not show activity in any of the assay solutions (Quintela et al. 2003a). Similarly, the fluoroquinolone ciprofloxacin did not show any activity in a previous study (Iglesias et al. 2002). The resistance to these antibiotics may be due to alterations in subunit A of the parasite's DNA gyrase, resulting from chromosomal mutations, and/or to alterations in cell permeability provoked by excessive intracellular concentrations of the antibiotic (Fuentes 1990). The activity of the tetracyclines, used in aquaculture as antibacterials, is markedly reduced in seawater (Herwig 1979, Iglesias et al. 2002). The same may occur with lomefloxacin, and indeed previous studies have noted that the bioavailability of quinolones may be reduced in seawater, through reduced drug uptake as a result of the presence of bivalent cations such as $\mathrm{Mg}^{2+}$ (Burka et al. 1997). Note, however, that lomefloxacin was similarly ineffective in PBS, so that the 
observed ineffectiveness may simply reflect a lack of activity against $P$. dicentrarchi.

Of all the studied naphthyridines, only compounds $2 \mathrm{f}$ and 50 caused $100 \%$ mortality at $50 \mathrm{mg} \mathrm{l}^{-1}$ or less in both assay solutions: MLC in PBS was 50 and $25 \mathrm{mg} \mathrm{l}^{-1}$ respectively, while MLC in seawater was $12.5 \mathrm{mg} \mathrm{l}^{-1}$ in both cases. No other naphthyridine derivate was active in either of these assay solutions, except for $2 \mathrm{e}$, which was effective in PBS at the high dose of $100 \mathrm{mg} \mathrm{l}^{-1}$ (see Table 1).

Of the pyridothienodiazines studied, compound 7 was the most effective, with an MLC of $12.5 \mathrm{mg} \mathrm{l}^{-1}$ in both PBS and seawater (Quintela et al. 2003a). Compound $\mathrm{H}-26$ was effective only in PBS $\left(50 \mathrm{mg} \mathrm{l}^{-1}\right.$, see Table 1), so it may be considered for in vivo oral administration, but its non-effectivity in seawater should be borne in mind when considering bath treatment.

Some of the pyridothienotriazines tested also showed good activity in both PBS and seawater (compounds $7 \mathrm{~h}, 9,12 \mathrm{~d}, 12 \mathrm{f}, 12 \mathrm{~m}, 12 \mathrm{~h}$ and $12 \mathrm{k}$; see Table 1 ). Compounds $7 \mathrm{~h}$ and 9 showed MLCs of $6.2 \mathrm{mg} \mathrm{l}^{-1}$ and $25 \mathrm{mg} \mathrm{l}^{-1}$ in PBS, and 3.1 and $25 \mathrm{mg} \mathrm{l}^{-1}$ in seawater, respectively (Quintela et al. 2003a). Compound 12k was the most active product detected, with MLCs of only $0.8 \mathrm{mg} \mathrm{l}^{-1}$ in PBS and $1.5 \mathrm{mg} \mathrm{l}^{-1}$ in seawater (Quintela et al. 2003a), comparable to the MLC of $0.8 \mathrm{mg} \mathrm{l}^{-1}$ in seawater displayed by the salicylanilides niclosamide and oxiclozanide (Iglesias et al. 2002). Other pyridothienotriazines were ineffective in seawater, but very active in PBS $(7 \mathrm{~g}$ and 6 a were effective at doses of 25 and $3.1 \mathrm{mg} \mathrm{l}^{-1}$, respectively, in this assay solution), so they may be considered for oral administration when testing their activity in vivo.

The pyridines and pyrazolopyrimidines tested in this study were ineffective in both assay solutions and are thus not included in Table 1. Previous studies have shown that some pyrazolopyrimidines are effective in vitro against Leishmania and Trypanosoma cruzi (Fish et al. 1985) or block trypomastigote-amastigote transformation in T. cruzi (Avila \& Avila 1987). Isoxazolpyrimidines were also ineffective, except for compound BR-102, which was active at high doses $(100 \mathrm{mg}$ $\mathrm{l}^{-1}$ ) in both PBS and seawater.

Pyrimidinic derivates showed low efficacy against this ciliate, with an effective dose of $100 \mathrm{mg} \mathrm{l}^{-1}$ in both PBS and seawater for compound PPC-19 and $100 \mathrm{mg}$ $\mathrm{l}^{-1}$ only in seawater for compound 6 (see Table 1 ).

In conclusion, 21 of the 85 newly synthesized compounds tested in the present study showed in vitro activity against Philasterides dicentrarchi in seawater and/or PBS, and 17 were effective as defined by $24 \mathrm{~h}$ MLC $\leq 50 \mathrm{mg} \mathrm{l}^{-1}$. The lowest MLC was obtained for the pyridothienotriazine $12 \mathrm{k}$. Low MLCs were also obtained for the pyridothienotriazines $7 \mathrm{~h}, 9,12 \mathrm{~d}, 12 \mathrm{f}, 12 \mathrm{~m}$ and $12 \mathrm{~h}$, for the pyridothienodiazine 7 , and for naphthyridines $2 \mathrm{f}$ and $5 \mathrm{o}$. Of the 12 commercial compounds, 6 were effective in PBS or seawater at a dose of $100 \mathrm{mg}$ $\mathrm{I}^{-1}$, except for the antibiotic norfloxacin that was effective at $50 \mathrm{mg} \mathrm{l}^{-1}$ in both PBS and seawater. All these compounds contain a piperazine ring in their chemical structure. In spite of the non-efficacy of simple piperazine against this parasite, the presence of this ring in a compound seems to enhance its antiprotozoal activity against $P$. dicentrarchi. If this proves to be true, a knowledge of the structure-activity relationships for these compounds would facilitate the development of effective drugs for the control of these pathogenic protozoans. Further trials are now underway to comprehensively evaluate the efficacy of these compounds in vivo.

Acknowledgements. We thank the Ministerio de Ciencia y Tecnología and the Xunta de Galicia for financial support for this research (grants BQU2002-01195, SAF2003-08765-C0301, AGL200304644, PGIDT02BTF20902PR, PGIDIT02RMA23 701PR and PGIDT03PXIC20908PN).

\section{LITERATURE CITED}

Avila JL, Avila A (1987) Defective transport of pyrazolopyrimidine ribosides in insensitive Trypanosoma cruzi wild strains is a parasite-stage specific and reversible characteristic. Comp Biochem Physiol B 87(3):489-495

Bernard C, Fenchel T (1996) Some microaerobic ciliates are facultative anaerobes. Eur J Protistol 32:293-297

Brun-Pascaud M, Fay M, Zhong M, Bauchet J, Dux-Guyot A, Pocidalo JJ (1992) Use of fluoroquinolones for prophylaxis of murine Pneumocystis carinii pneumonia. Antimicrob Agents Chemother 36:470-472

Burka JF, Hammell KL, Horsberg TE, Jonson GR, Rainnie DJ, Speare DJ (1997) Drugs in salmonid aquaculture-a review. J Vet Pharmacol Therap 20:333-349

Céspedes AJ, Portal PF (1998) Actualidad y perspectivas de la farmacología de drogas antibacterianas. Rev Cubana Med Milit 27(2):85-93

Dragesco A, Dragesco J, Coste F, Gasc C, Romestand B, Raymond J, Bouix G (1995) Philasterides dicentrarchi, n. sp. (Ciliophora, Scuticociliatida), a histophagous opportunistic parasite of Dicentrarchus labrax (Linnaeus. 1758), a reared marine fish. Eur J Protistol 31:327-340

Drlica K, Franco RJ (1988) Inhibitors of DNA topoisomerases. Biochemistry 27:2253-2259

Estévez I, Raviña E, Sotelo E (1998) Pyridazines. XV. Synthesis of 6-aryl-5-amino-3(2H)-pyridazinones as potential platelet aggregation inhibitors. J Heterocyclic Chem 35: 1421-1428

Fish WR, Marr JJ, Berens RL, Looker DL, Nelson DJ, LaFon SW, Balber AE (1985) Inosine analogs as chemotherapeutic agents for African trypanosomes: metabolism in trypanosomes and efficacy in tissue culture. Antimicrob Agents Chemother 27(1):33-36

Fuentes J (1990) Fluoroquinolonas. Información Farmacológica. Iatreia 3(3):158-164

Herwig N (1979) Handbook of drug and chemicals used in the treatment of fish diseases. Charles C Thomas Publisher, Springfield, IL 
Iglesias R, Paramá A, Álvarez MF, Leiro J, Fernández J, Sanmartín ML (2001) Philasterides dicentrarchi (Ciliophora, Scuticociliatida) as the causative agent of scuticociliatosis in farmed turbot (Scophthalmus maximus) in Galicia (NW Spain). Dis Aquat Org 46:47-55

Iglesias R, Paramá A, Álvarez MF, Leiro J, Sanmartín ML (2002) Antiprotozoals effective in vitro against the scuticociliate fish pathogen Philasterides dicentrarchi. Dis Aquat Org 49:191-197

Montay G, Goueffon Y, Roquet F (1984) Absorption, distribution, metabolic fate and elimination of pefloxacin mesilate in mice, rats, monkeys and humans. Antimicrob Agents Chemother 25:463-472

Quintela JM, Peinador C, Botana L, Estévez M, Riguera R (1997) Synthesis and antihistaminic activity of 2-guanadino 3-cyanopyridines and pyrido [2, 3-d]-pyrimidines. Bioorg Med Chem 5:1543-1553

Quintela JM, Peinador C, Veiga C, González L, Botana L, Alfonso A, Riguera R (1998a) Synthesis and antiallergic activity of pyridothienopyrimidines. Bioorg Med Chem 6: 1911-1925

Quintela JM, Peinador C, Veiga C, Botana L, Alfonso A, Riguera R (1998b) Synthesis, antihistaminic and cytotoxic activity of pyridothieno- and pyridodithienotriazines. Eur J Med Chem 33(11):887-897

Quintela JM, Peinador C, González L, Riguera R, Rioja I, Terencio MC, Ubeda A, Alcaraz MJ (1999) Synthesis and pharmacological evaluation of some 8-cyanopyrido [3', 2': $4,5]$ trieno [3, $2-\mathrm{d}$ ] triazine derivatives as inhibitors of nitric oxide and eicosanoid biosynthesis. J Med Chem 42: 4720-4724

Quintela JM, Peinador C, González L, Iglesias R, Paramá A, Álvarez F, Sanmartín ML, Riguera R (2003a) Piperazine Nsubstituted naphthyridines, pyridothienopyrimidines and pyridothienotriazines: new antiprotozoals active against Philasterides dicentrarchi. Eur J Med Chem 38:265-275

Editorial responsibility: Wolfgang Körting,

Hannover, Germany
Quintela JM, Peinador C, González L, Alcaraz MJ, Riguera R (2003b) 6-Dimethylamino 1H-Pyrazolo[3, 4-d]pyrimidine derivatives as new inhibitors of inflammatory mediators in intact cells. Bioorg Med Chem 11:863-868

Raviña E, Cid J, Negreira J, Castro ME and 5 others (1995) Piperazinomethyl tetralines: synthesis and affinities for $\mathrm{D}_{1}$, $\mathrm{D}_{2}$ and $5-\mathrm{HT}_{2 \mathrm{~A}}$ receptors. Chem Pharm Bull 43:1234-1237

Raviña E, Fueyo J, Masaguer CF, Negreira J and 9 others (1996) Synthesis and affinities for dopamine $\left(\mathrm{D}_{2}\right)$ and 5hydroxytryptamine $\left(5-\mathrm{HT}_{2 \mathrm{~A}}\right)$ receptors of 1-(Benzoylpropyl)-4-(1-oxocycloalkyl-2-ethyl)-piperazines as cyclic butyrophenone derivatives. Chem Pharm Bull 44:534-541

Raviña E, Negreira J, Cid J, Masaguer CF and 10 others (1999) Conformationally constrained butyrophenones with mixed dopaminergic $\left(\mathrm{D}_{2}\right)$ and serotoninergic (5$\mathrm{HT}_{2 \mathrm{~A}}, 5-\mathrm{HT}_{2 \mathrm{C}}$ ) affinities: synthesis, pharmacology, 3DQSAR, and molecular modeling of (aminoalkyl)benzoand thienocycloalkanones as putative atypical antipsychotics. J Med Chem 42:2774-2797

Tojo JL, Santamarina MT (1998a) Oral pharmacological treatments for parasitic diseases of rainbow trout Oncorhynchus mykiss. III. Ichthyobodo necator. Dis Aquat Org 33:195-199

Tojo JL, Santamarina MT (1998b) Oral pharmacological treatments for parasitic diseases of rainbow trout Oncorhynchus mykiss. II. Gyrodactylus sp. Dis Aquat Org 33: 187-193

Tojo JL, Santamarina MT (1998c) Oral pharmacological treatments for parasitic diseases of rainbow trout Oncorhynchus mykiss. I. Hexamita salmonis. Dis Aquat Org 33: $51-56$

Vidal A, Ferrándiz ML, Ubeda A, Guillén I and 5 others (2000) Effects of some isoxazolpyrimidine derivatives on nitric oxide and eicosanoid síntesis. Life Sci 66(9):125-131

Wang CC (1984) Parasite enzymes as potential targets for antiparasitic chemotherapy. J Med Chem 27(1):1-10

Submitted: March 5, 2004; Accepted: July 12, 2004

Proofs received from author(s): October 14, 2004 